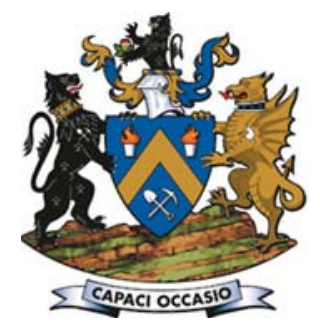

\title{
The influence of particle size distribution on the properties of metal- injection-moulded 17-4 PH stainless steel
}

\author{
by M. Seerane* ${ }^{*}$ P. Ndlangamandla ${ }^{\dagger}$ and R. Machaka*
}

\begin{abstract}
Synopsis
Metal injection moulding (MIM) is a near-net-shaping powder metallurgy technique suitable for the cost-effective mass production of small and complex components. In this paper, the effects of the metal powder particle size on the final properties of 17-4 PH stainless steel are reported. Three different particle sizes $\left(d_{50} 33.0,7.91\right.$ and $\left.4.04 \mu \mathrm{m}\right)$ were used to prepare the injectable MIM feedstocks using a CSIR-developed wax-based binder system at a fixed solids loading of $60 \mathrm{vol} . \%$. The distribution slope parameter and the rheological flow index behaviour were used to predict the flowability of the feedstocks. The effects of the particle size on MIM products were established. The results are discussed in terms of the subsequent microstructural and mechanical properties of MIM 17-4 PH stainless steel against the established MPIF Standard 35.

Keywords

metal injection moulding, MIM, particle size distribution, 17-4 PH stainless steel, densification, properties.
\end{abstract}

\section{Introduction}

Metal injection moulding (MIM) is a near-netshape manufacturing process established as an alternative to produce complex small-tomedium shaped components that were previously fabricated by conventional methods at higher costs (Attia and Alcock, 2011; Todd and Sidambe, 2013).

Although recent advances in micromanufacturing (mainly machining and electrodeposition-based) have enabled the fabrication of complex micro-size geometries directly into miniaturized parts, these processes are generally neither routine nor easily accessible at present (Attia and Alcock, 2011).

Typically, the MIM process consists of four steps: mixing, injection moulding, debinding and sintering. Mixing involves blending of the desired metal powder composition with carefully selected multicomponent organic binders at the right proportion. This mixture, which is called feedstock, is then injected into a mould of a required shape to form a 'green part'. Debinding is the removal of the binders by chemical, thermal, or catalytic means while maintaining the shape of the part. Finally, the debound part is sintered to a full or near-full density part (Sotomayor, Varez and Levenfeld, 2010). The MIM process is essentially a combination of plastic injection moulding with conventional powder metallurgy technologies.

According to the literature (German and Rose, 1997; Khakbiz, Simchi and Bagheri, 2005; Seerane et al., 2013), the mechanical properties of the final MIM-produced components are certainly influenced in the fabrication stages in the MIM processing, as well as by the selection of the starting powder and binder materials. Therefore, understanding the powder characteristics is critical for the success of the MIM process.

Powder particle sizes (German and Rose, 1997; German, 2005) play a significant role in realizing a dense sintered part at the minimum shrinkage (Ma et al., 2014; Sotomayor et al., 2010). Finer powder particles result in smaller moulding defects, increase melt viscosity, higher sintering rates and shrinkage and better surface finish. However, some of the disadvantages encountered with the use of finer particles include agglomeration, which adversely affects the homogeneity of the feedstock, necessitating longer debinding times and higher powder procurement cost. Coarser powder particles, in contrast, give higher packing efficiency, reduced sintering shrinkage rates, shorter debinding times and are typically cheap and easy to handle, but the product quality is often inferior (Bose et al., 2008; German, 1992; Hausnerova, Kitano and Saha, 2010).

The influence of particle size distribution on mouldability of the feedstock is also a crucial factor in the chain of the MIM process (Amin, Jamaludin and Muhamad, 2009). Two

* Light Metals, Materials Science and Manufacturing, Council for Scientific and Industrial Research, Pretoria, South Africa.

+ Department of Materials Science and Metallurgical Engineering, University of Pretoria, South Africa.

(c) The Southern African Institute of Mining and Metallurgy, 2016. ISSN 2225-6253. This paper was first presented at the AMI Ferrous and Base Metals Development Network Conference 2016 19-21 October 2016, Southern Sun Elangeni Maharani, KwaZulu-Natal, South Africa. 


\section{The influence of particle size distribution on the properties of metal-injection}

parameters that are used to predict the mouldability of the feedstock are the distribution slope parameter (Sw) and flow behaviour index $(n)$. The former parameter represents the measure of particle size range and is defined as (German and Bose, 1997):

$$
S_{w}=\frac{2.56}{\log \left(\frac{d_{90}}{d_{10}}\right)}
$$

where the numerator represents the fact that $d_{10}$ and $d_{90}$ are 2.56 standard deviations apart on a Gaussian distribution; however, powders usually follow a lognormal distribution and the logarithmic size is appropriate for obtaining Gaussian behaviour. The average particle size, $d_{50}$ and $S_{w}$ are important measures of a powder. The parameter $S_{w}$ is the slope of the lognormal cumulative distribution and is similar to a coefficient of variation or standard deviation. A narrow particle size distribution is implied by larger values of $S_{w}$ and a wider distribution corresponds to small values of $S_{w}$. Powders that exhibit a $S_{w}$ of 2 (very broad distributions) are easier to mould, while some more difficult powders to mould exhibit $S_{w}$ values between 4 and 5 . A very narrow particle size distribution with $S_{w}$ greater than 7 is the most difficult to mould.

The flow behaviour index ( $n$ value) indicates the sensitivity of the feedstock's viscosity to shear rate variations (Ahn et al., 2009); smaller values (typically less than 1) indicating higher shear sensitivity and more pseudo-plasticity of the feedstock and hence better viscosity response to shear rate changes. For such feedstocks, mould filling is therefore easier, especially at higher shear rates. Amin et al. (2009) concluded that fine particles exhibit low $n$ values and thus greater pseudo-plastic behaviour of the feedstock. It is important that the $n$ value for each feedstock is calculated in order to predict the mouldability. The following rheology equation is used to estimate the values of $n$ (Huang, Liang and $\mathrm{Qu}, 2003)$ :

$$
\eta=K \dot{\gamma}^{n-1}
$$

where $\eta$ is the viscosity of the feedstock and $K$ a constant. The slope of the $\log \eta$ versus $\log \dot{\gamma}$ graph is $n-1$, from which $n$ can be deduced.

There has been a limited amount of work on the effects of particle size and particle size distribution on the mouldability and sinterability of MIM powders. Most work available (Bricout et al., 2013; González-Gutiérrez, Stringari and Emri, 2012; Mannschatz, Muller and Moritz, 2011; Schwartzwalder, 1949) puts considerable emphasis on the influence of particle shape, tailored particle size distribution and powder loading on the flowability of MIM feedstock and hence the final mechanical properties of the sintered parts. Mamen et al. ( 2015), however, studied the effect of particle size on the sintering behaviour of tungsten parts produced by MIM, but failed to report on the mechanical properties of their sintered parts. The present work is a study of the influence of the starting powder particle size on the mechanical properties (tensile strength, hardness and density and shrinkage factors) of metal-injection-moulded 17-4 PH stainless steel parts.

\section{Experimental}

\section{Materials}

The 17-4 PH stainless steel powder materials: $-45 \mu \mathrm{m}$ Grade 630 (Praxair Surface Technologies), $-15 \mu \mathrm{m}$ and $-5 \mu \mathrm{m}$ (Epson Atmix Corp., JP) were used for this study. Figure 1 shows the sizes and spherical morphologies of the metal powders as observed under the JEOL JSM-6510 scanning electron microscope (SEM).

Table I summarizes the size distributions of the metal particles obtained using a laser-scattering particle size analyser (Microtrac Bluewave). The material codes PS-45, PS-15 and PS-5 represent the particle sizes $-45 \mu \mathrm{m},-15 \mu \mathrm{m}$ and $-5 \mu \mathrm{m}$ respectively.

Table II shows the chemical compositions of the metal powders obtained from the supplier's materials data specification sheets.

\section{Table I}

Size distributions of 17-4 PH stainless steel powders

\begin{tabular}{|l|c|c|c|}
\hline Material code & $\boldsymbol{d}_{\mathbf{1 0}}(\boldsymbol{\mu \mathrm { m }})$ & $\boldsymbol{d}_{\mathbf{5 0}}(\boldsymbol{\mu \mathrm { m } )}$ & $\boldsymbol{d}_{\mathbf{9 0}}(\boldsymbol{\mu \mathrm { m } )}$ \\
\hline PS-45 & 12.3 & 33.0 & 50.3 \\
PS-15 & 2.65 & 7.91 & 23.1 \\
PS-5 & 1.98 & 4.04 & 7.90 \\
\hline
\end{tabular}

Table II

Chemical compositions (wt \%) of the starting powder materials

\begin{tabular}{|l|c|c|c|c|c|c|c|}
\hline & $\mathbf{S i}$ & $\mathbf{M n}$ & $\mathbf{N i}$ & $\mathbf{C r}$ & $\mathbf{C u}$ & $\mathbf{N b}$ & $\mathbf{F e}$ \\
\hline $\begin{array}{l}\text { FE-276-3 } \\
17-4 \mathrm{PH}\end{array}$ & $\begin{array}{c}1.0 \\
\leq 0.5\end{array}$ & $\leq 0.3$ & $\begin{array}{c}4.0 \\
3.0-5.0\end{array}$ & $\begin{array}{c}16.0 \\
15.5-17.5\end{array}$ & $\begin{array}{c}3.0 \\
3.0-5.0\end{array}$ & $\begin{array}{c}0.25 \\
0.15-0.45\end{array}$ & $\begin{array}{c}\text { Bal. } \\
\text { Bal. }\end{array}$ \\
\hline
\end{tabular}
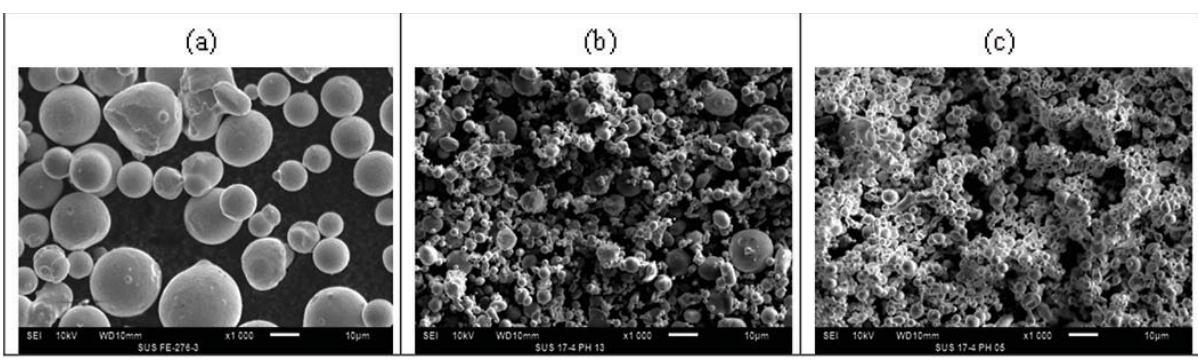

Figure 1-SEM images of 17-4 PH stainless steel powder at $1000 \times$ magnification. (a) $-45 \mu \mathrm{m}$, (b) $-15 \mu \mathrm{m},(\mathrm{c})-5 \mu \mathrm{m}$ 


\section{The influence of particle size distribution on the properties of metal-injection}

\section{Feedstock preparation and injection moulding}

We prepared three feedstocks by mixing metallic powder materials with a custom wax-polymer binder system developed at CSIR. The binder system consists of paraffin wax, low-density polyethylene, polypropylene and stearic acid. The solids loading, which is the volume ratio of the solid powder to the total volume of the powder and binder, was kept constant at 60 vol.\%. The feedstocks were labelled on the basis of powder size and solids loading; the nomenclature is presented in Table III.

The feedstocks were prepared by means of a sigma-type blade mixer (4223 Jones Industrial mixer) using a rotation frequency of $90 \mathrm{r} / \mathrm{min}$ for at least 1 hour at $140^{\circ} \mathrm{C}$ in air. Upon cooling, all feedstocks were appropriately granulated after mixing and were re-mixed for a further 30 minutes to improve homogeneity.

The feedstocks were injection-moulded using a $40 \mathrm{t}$ ARBURG Allrounder 270U 400-70 injection moulding machine. The feedstocks were injection-moulded into MPIF standard 'dogbone' shape tensile specimens of dimensions $89 \mathrm{~mm}$ (overall length), $40 \mathrm{~mm}$ (gauge length), $14.8 \mathrm{~mm}$ (grip section diameter) and $5 \mathrm{~mm}$ (gauge section diameter) The product of injection moulding is called a 'green component'. The injection moulding process parameters (injection temperature, speed and pressure and mould temperature) were optimized in previous work (Seerane, Chikwanda and Machaka, 2015).

\section{Debinding and sintering}

The debinding of the injection-moulded components was performed using two techniques: solvent extraction and thermal debinding, in that order. Solvent debinding involves the immersion of the green component in $n$-heptane at $60^{\circ} \mathrm{C}$ for 24 hours to extract the solvent-soluble wax and stearic acid binder fractions. The samples were then dried overnight to reject residual solvent. In order to avoid breakage of the fragile debound parts, the thermal debinding precedes the sintering stage; both were carried out in a Carbolite tube furnace under a controlled flowing argon atmosphere. The solvent-debound samples were placed in an alumina crucible, loaded into the furnace and heated from room temperature to $550^{\circ} \mathrm{C}$ at $1.0^{\circ} \mathrm{C} / \mathrm{min}$ The samples were held at $550^{\circ} \mathrm{C}$ for 1 hour to completely remove the remaining binder components. The furnace temperature was then ramped up to $1300^{\circ} \mathrm{C}$ at $10^{\circ} \mathrm{C} / \mathrm{min}$ for sintering. Sintering was performed for 4 hours, then the furnace was cooled. The argon gas flow was maintained at $1.0 \mathrm{~L} / \mathrm{min}$. The debinding process parameters were investigated in prevous work (Machaka and Chikwanda, 2014; Machaka, Seerane and Chikwanda, 2014; Seerane et al., 2015).

\section{Post-sintering analysis}

Sintered samples were evaluated for density and shrinkage level and tested for mechanical properties like apparent hardness and tensile strength. The linear shrinkage level of the sintered samples was measured against the as-moulded green parts using a high-precision Vernier calliper. Sintered density measurement was performed on a precision analytical balance (OHAUS) based on the Archimedes principle. The apparent hardness measurements were carried out by using Vicker's scale through the application of $500 \mathrm{~g}$ load for 10 seconds, according to ASTM-E384 standard, on an automated microhardness tester (FM-700). Tensile testing was done on an INSTRON ${ }^{\mathrm{TM}}$ Servo Hydraulic 1342 test instrument at the constant rate of $0.5 \mathrm{~mm} / \mathrm{min}$. Microstructural analysis was done using a Leica DMI500 M optical microscope.

\section{Results and discussion}

\section{Mouldability}

The evaluation of the feedstock mouldability was based on the distribution slope parameter and the flow behaviour index. Table IV summarizes the estimated values of $S_{w}$ and $n$. The $S_{w}$ values for feedstocks PS-45-60 and PS-5-60 indicate that the powders (PS-45 and PS-5) used to prepare the feedstocks are likely to be difficult to mould. The data for feedstock PS-15-60 indicates that the powder (PS-15) used to prepare the feedstock has a wider particle size distribution and hence better mouldability due to the lower $S_{w}$ value of 2.72. On the other hand, feedstock PS-15-60 has the lowest $n$ value of 0.331 and therefore a higher shear sensitivity and better viscosity response to shear rate variations. From these observations it can be deduced that feedstock PS-15-60 is expected to be mouldable during injection moulding.

\section{Shrinkage}

Figure 2 depicts the shrinkage difference between the asmoulded green, solvent-debound and sintered components. Surface appearance of specimens (a) - (c) gives an indication of the binder lost from the green state to the sintered state and this equates to the level of shrinkage that occurred. Specimen (b) underwent solvent debinding and no significant shrinkage difference is observed relative to the as-moulded part.

Figure 3 shows the shrinkage levels of the specimens at different particle sizes. It can be clearly seen that the shrinkage behaviour is sensitive to the feedstock particle size. The PS-45-60 specimen (larger starting particle size) shows a relatively lower shrinkage level and this is advantageous for controlled dimensional tolerance. As

\section{Table III}

\section{Formulation of the feedstocks used in this study}

\begin{tabular}{|l|c|}
\hline Feedstock ID & Feedstock details \\
\hline PS-45-60 & 60 vol.\%, powder: $-45 \mu \mathrm{m}$ \\
PS-15-60 & 60 vol.\%, powder: $-15 \mu \mathrm{m}$ \\
PS-5-60 & 60 vol. \%, powder: $-5 \mu \mathrm{m}$ \\
\hline
\end{tabular}

Table IV

The parameters representing the mouldability of the feedstocks

\begin{tabular}{|l|c|c|}
\hline Material code & $\boldsymbol{S}_{\boldsymbol{w}}$ & $\boldsymbol{n}$ \\
\hline PS-45-60 & 4.18 & 0.563 \\
PS-15-60 & 2.72 & 0.331 \\
PS-5-60 & 4.26 & 0.390 \\
\hline
\end{tabular}




\section{The influence of particle size distribution on the properties of metal-injection}

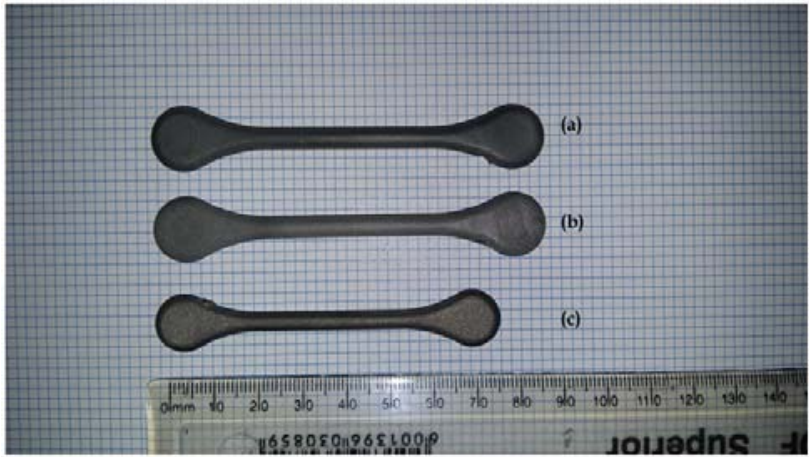

Figure 2-MIM parts of 17-4 PH stainless steel showing shrinkage differentiation: (a) as-moulded, (b) solvent-debound, (c) sintered

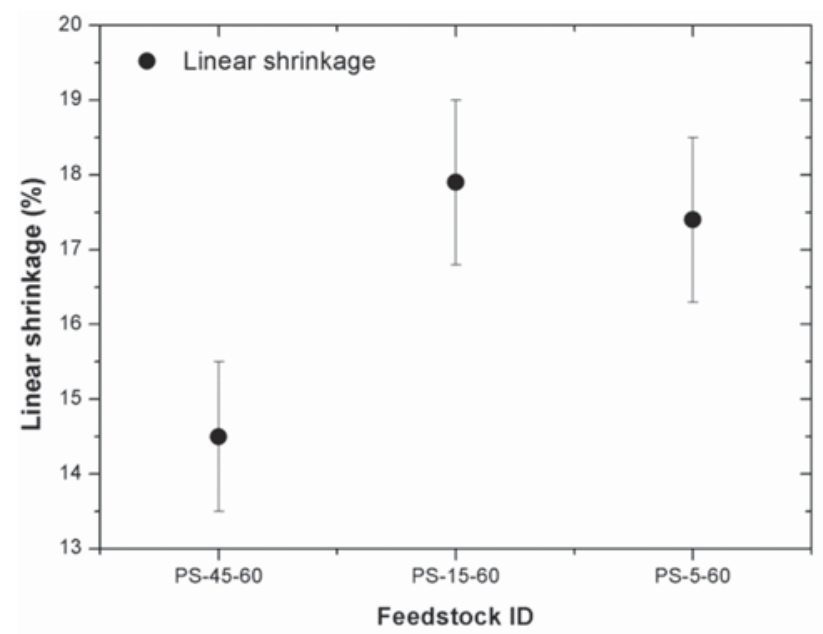

Figure 3-Linear shrinkage of sintered parts at different particle sizes and a fixed starting powder loading of $60 \mathrm{vol} . \%$

expected, the PS-15-60 and PS-5-60 specimens (smaller particle size) exhibit higher shrinkage levels. The latter result is expected, since smaller particles have a larger specific surface area, necessitating a larger amount of binder which therefore increases the shrinkage level during sintering (Hartwig et al., 1998). PS-15-60 and PS-5-60 specimens do not show a significant difference in their shrinkage levels; however, the PS-5-60 specimen indicates a slightly lower average shrinkage level and this can be attributed to the presence of an oxidation film on the surface of the particles that delays sintering rate and hence shrinkage.

\section{Sintering density and microstructure}

Sintered MIM parts are expected to have some residual porosity and usually have densities ranging from 95-99\% of the theoretical density (Todd and Sidambe, 2013). It is known in powder metallurgy that finer starting powder particles have better sinterability and therefore tend to achieve relatively higher sintered densities. However, against expectations, the data in Figure 4 seems to indicate that an optimal sintered density is between $94 \%$ and $97 \%$ of the theoretical density. Specimen PS-15-60 has the highest density of $97 \%$, which conforms to the range quoted in the literature. According to German(1992), for example, the lower density of the specimen PS-5-60 may be the result of particle agglomeration that leads to poor packing density and non-homogeneous feedstock; and hence deteriorated sinterability. In addition, finer powder particles are more prone to surface oxidation (Ye, Liu and Hong, 2008) and this may hinder the sinterability of the localized particles. The higher sintered density of the specimen PS-15-60 can be attributed to a combination of the best mouldability of PS-15-60 feedstock (as shown in Table IV) and the finer starting powder particles to drive sintering.

To complement the sintered density observation, Figure 5 shows the microstructures of the sintered specimens. It can be seen that the finer the starting powder particle size the finer the observed pores are, in general. Specimen PS-45-60 shows, as expected, relatively larger pores that are not particularly uniformly distributed. Specimens PS-15-60 and PS-560 , on the other hand, shows abundant and uniformly

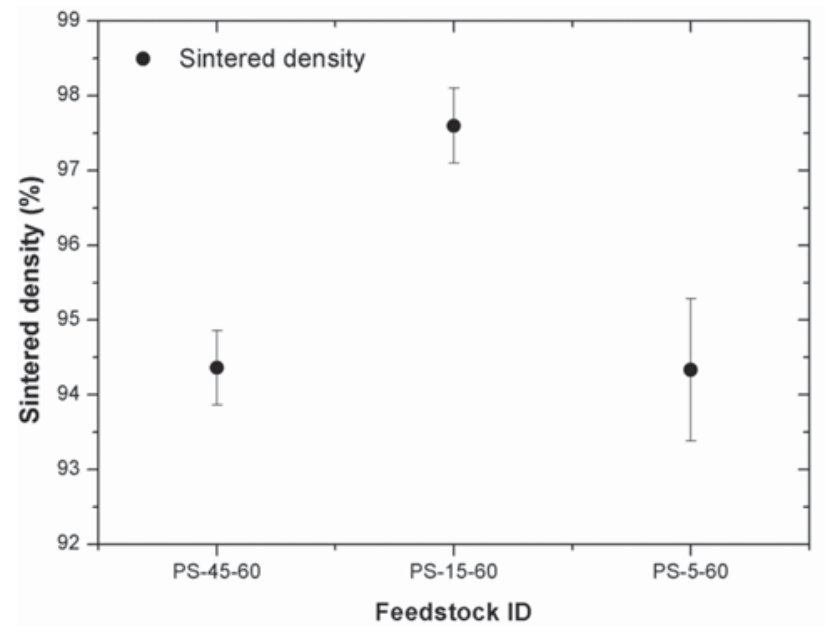

Figure 4-The effect of particle size on the density of sintered parts (a)

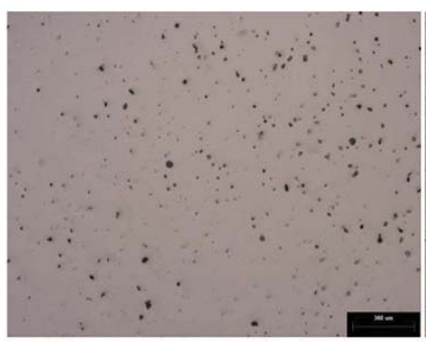

(b)

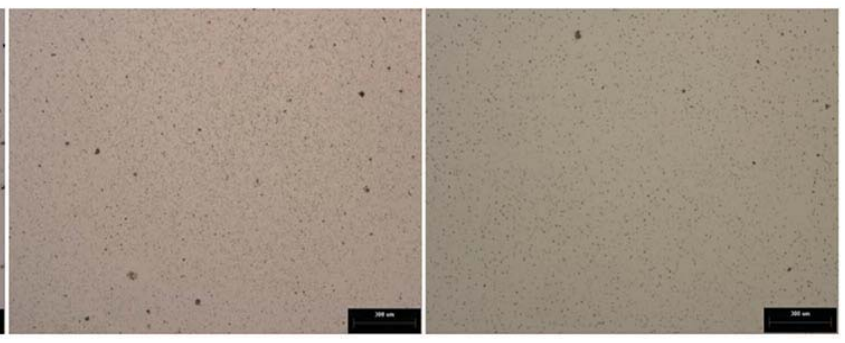

Figure 5-Optical micrographs of the as-sintered parts: (a) PS-45-60, (b) PS-15-60, (c) PS-5-60. Scale bar $300 \mu \mathrm{m}$ at $5 \times$ magnification) 


\section{The influence of particle size distribution on the properties of metal-injection}

distributed fine pores. However, a few large pores on specimen PS-15-60 can be seen. It is possible that the sum of uniformly distributed fine pores in the PS-5-60 specimen compromises sinterability.

\section{Mechanical properties}

Figure 6 summarizes the measured mechanical properties of the sintered parts and the respective as-sintered $17-4 \mathrm{PH}$ stainless steel minimum MPIF Standard 35 specifications (MPIF, 2007).

The experimentally measured properties of the PS-45-60 specimen, as presented in Figure 6, are consistently inferior to the minimum tensile property values outlined in the MPIF Standard 35. The PS-5-60 and the PS-15-60 specimens meet most of the minimum standards for density, yield strength, ultimate tensile strength, hardness and elongation. However, the PS-15-60 specimen fails to meet the minimum standard for elongation.

The tensile properties generally improve with a decreasing particle size. This can be attributed to the increasing hardness as the particle size becomes finer. A correlation between hardness and tensile strength is in conformance with the findings in Gülsoy, Özgün and Bilketay (2016) and this relationship is also known to be common (Gaško and Rosenberg, 2011; Shen and Chawla, 2001).

It is apparent therefore that the yield strength, ultimate tensile strength and hardness generally increase as the particle size becomes finer. The influence of particle size on hardness is consistent with the work reported by Srivatsan et al. (2002). The lower hardness values of the PS-45-60 and PS-5-60 specimens can be attributed to the considerably larger pore volumes (Figure 5).

\section{Conclusions}

Feedstocks of fixed metal powder loading of 60 vol.\% and different metal powder particle sizes of $-45,-15$ and $-5 \mu \mathrm{m}$ were successfully prepared and evaluated for metal injection moulding.

> All the feedstocks exhibited a pseudo-plastic flow property, indicating their general suitability for injection moulding. The starting powder particle size appears to affect the feedstock mouldability; rheological parameters of specimen PS-5-60 indicate moulding difficulty, while PS-15-60 is expected to have superior mouldablity during injection

> The effect of the starting powder particle size distribution on the sintered density and shrinkage levels was investigated. A larger particle size yielded minimum shrinkage levels and inferior final sintered densities. Particle agglomeration, poor packing efficiency and non-homogeneous feedstock pseudoplastic flow properties were identified as reasons for the inferior mouldability of the PS-5-60 feedstocks

> The PS-5-60 material has generally superior mechanical properties and meets the standard in all respects.

\section{Acknowledgements}

The contributions of NM, HKC, Ntate SP and PR are duly recognized. The authors are grateful to the DST and the CSIR for financial support. The authors are also indebted to Atmix Corp. (JP) for the supply of powder materials used in this study.
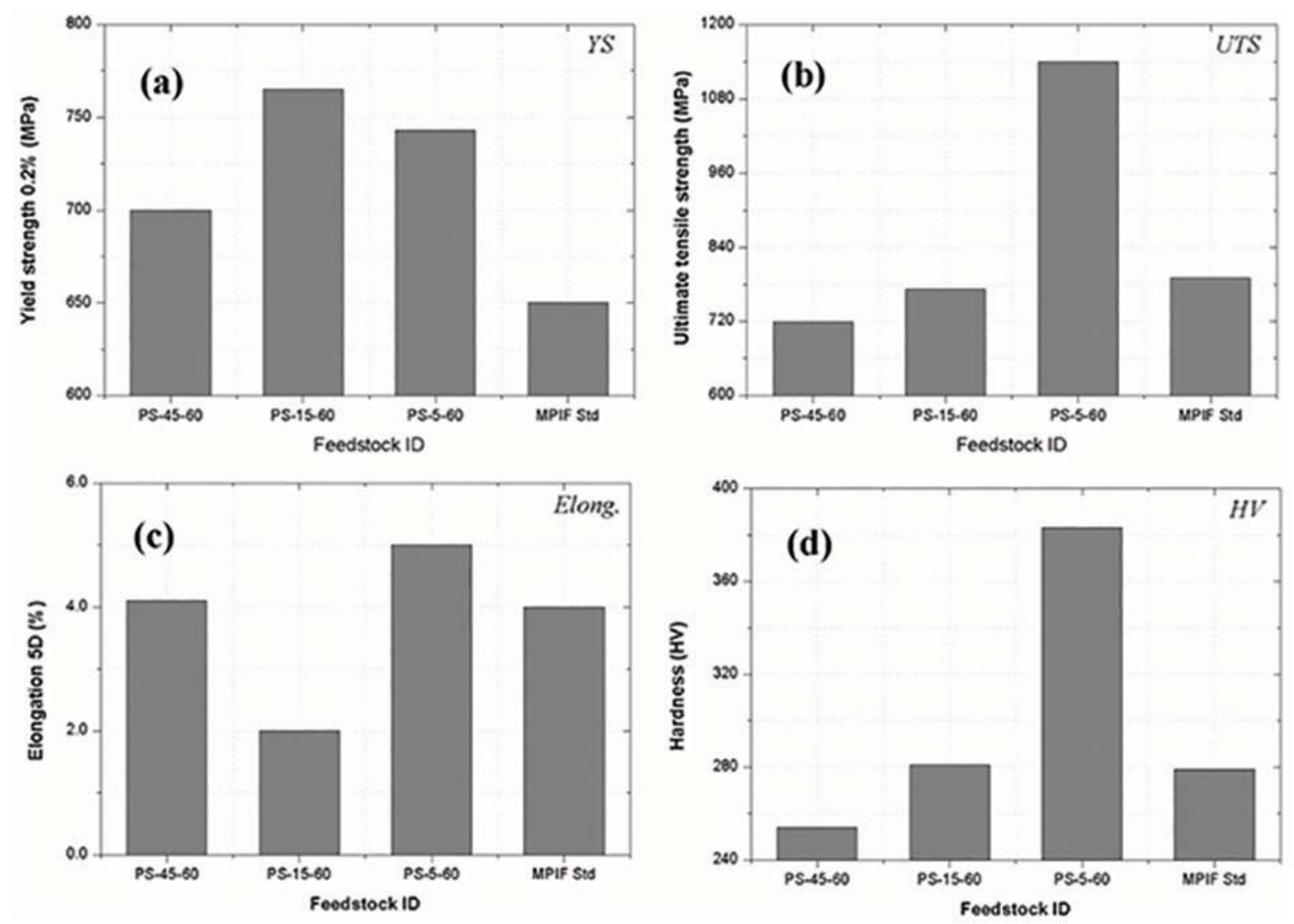

Figure 6-As-sintered MIM parts compared with MPIF Standard 35 (Materials Standard for Metal Injection Moulded Parts) 


\section{The influence of particle size distribution on the properties of metal-injection}

\section{References}

Ahn, S., PArk, S.J., Lee, S., Atre, S.V. and German, R.M. 2009. Effect of powders and binders on material properties and molding parameters in iron and stainless steel powder injection molding process. Powder Technology, vol. 193, no. 2. pp. 162-169.

Amin, S.Y.M., Jamaludin, K.R. and MuHAmad, N. 2009. Rheological properties of Ss316L Mim feedstock prepared with different particle sizes and powder loadings. Journal of the Institution of Engineers, Malaysia, vol. 7, no. 2. pp. 59-63.

AtтiA, U.M. and Alсоск, J.R. 2011. A review of micro-powder injection moulding as a microfabrication technique. Journal of Micromechanics and Microengineering, vol. 21, no. 4. pp. 43001-43001.

Bose, A., Otsuka, I., Yoshida, T. and Toyoshima, H. 2008. Faster sintering and lower costs with ultra-fine MIM powders. Metal Powder Report, vol. 63, no. 5. pp. 25-30.

Bricout, J., Gelin, J., Ablitzer, C., Matheron, P. and Brothier, M. 2013. Influence of powder characteristics on the behaviour of PIM feedstock. Chemical Engineering Research and Design, vol. 91. pp. 2484-2490.

GAšKo, M. and Rosenberg, G. 2011. Correlation between hardness and tensile properties in ultra-high strength dual phase steels. Materials Engineering, vol. 18. pp. 155-159.

German, R.M. 1992. Prediction of sintered density for bimodal powder mixtures. Metallurgical and Materials Transactions A, vol. 23A, May. pp. 1455-1465.

German, R.M. 2005. Powder Metallurgy and Particulate Materials Processing. Metal Powder Industries Federation, Princeton, NJ, USA.

German, R.M. and Bose, A. 1997. Injection Molding of Metals and Ceramics. Metal Powder Industries Federation, Princeton, NJ, USA.

GonZÁlez-GutiérReZ, J., Stringari, G.B. and Emri, I. 2012. Powder Injection molding of metal and ceramic parts. Intech. pp. 65-88.

GÜLSOY, H.Ö., ÖZGÜN, Ö. and BILKETAY, S. (2016). A powder injection molding of Stellite 6 powder : sintering, microstructural and mechanical properties. Materials Science and Engineering A, vol. 651. pp. 914-924.

Hartwig, T., Veltl, G., Petzoldt, F., Kunze, H., Scholl, R. and Kieback, B. (1998). Powders for metal injection molding. Journal of the European Ceramic Society, vol. 18. pp. 1211-1216.

Hausnerova, B., KitAno, T. and SAHA, P. 2010. Effect of particle size distribution on the flow behaviour of powder injection moulding materials. Proceedings of the 3rd WSEAS International Conference on Engineering Mechanics, Structures and Engineering Geology, Corfu. Martin, O. and Zheng, X. (eds.). pp. 192-194.

Huang, B., Liang, S. and Qu, X. 2003. The rheology of metal injection molding. Materials Processing Technology, vol. 13. pp. 132-137.

Khakвiz, M., Simchi, A. and BAgheri, R. 2005. Analysis of the rheological behavior and stability of 316L stainless steel-TiC powder injection molding feedstock. Materials Science and Engineering A, vol. 407, no. 1-2. pp. 105-113.
Ma, J., Qin, M., Zhang, L., Tian, L., Li, R., Chen, P. and Qu, X. 2014. Effect of ball milling on the rheology and particle characteristics of $\mathrm{Fe}-50 \% \mathrm{Ni}$ powder injection molding feedstock. Journal of Alloys and Compounds, vol. 590. pp. 41-45.

МАснAKA, R. and CHIKWANDA, H.K. 2014. Kinetics of titanium metal injection moulding feedstock thermal debinding. Proceedings of Light Metals Technologies 2015, Port Elizabeth. Chikwanda, H.K. and Chikosha, S. (eds.). pp. 1-6.

MachaKa, R., Seerane, M. and ChiKwanda, H.K. 2014. Binder development for metal injection moulding: a CSIR perspective. Advances in Powder Metallurgy and Particulate Materials - 2014, Proceedings of the 2014 World Congress on Powder Metallurgy and Particulate Materials, PM 2014. Metal Powder Industries Federation Princeton, NJ. pp. 443-458.

Mamen, B., Song, J., Barriere, T. and Gelin, J. 2015. Experimental and numerical analysis of the particle size effect on the densi fi cation behaviour of metal injection moulded tungsten parts during sintering. Powder Technology, vol. 270. pp. 230-243.

Mannschatz, A., Muller, A. and Moritz, T. (2011). Influence of powder morphology on properties of ceramic injection moulding feedstocks. Journal of the European Ceramic Society, vol. 31, no. 14. pp. 2551-2558.

MPIF. 2007. Materials standard for metal injection molded parts. MPIF Standard 35, (2007 edn.) Metal Powder Industries Federation, Princeton, NJ. pp. 19-19.

SCHWARTZWALDER, K. 1949. Injection molding of ceramic materials. Bulletin of the American Ceramic Society, vol. 28, no. 11. pp. 459-461.

Seerane, M., ChiKwanda, H. and MachaKa, R. 2015. Determination of optimum process for thermal debinding and sintering using Taguchi method. Materials Science Forum, vol. 829. pp. 138-144.

Seerane, M.N., ChiKWAnda, H.K., Focke, W. and MachaKa, R. 2013. Investigating the powder loading of gas atomised Ti6Al4V powder using an 'in-house' binder for MIM. Advanced Metals Initiative: Precious Metals 2013. Southern African Institute of Mining and Metallurgy, Johannesburg.

SHEN, Y. and CHAwLA, N. 2001. On the correlation between hardness and tensile strength in particle reinforced metal matrix composites. Materials Science and Engineering A, vol. 297. pp. 44-47.

Sotomayor, M.E., VARez, A. and Levenfeld, B. 2010. Influence of powder particle size distribution on rheological properties of $316 \mathrm{~L}$ powder injection moulding feedstocks. Powder Technology, vol. 200, no. 1-2. pp. 30-36.

Srivatsan, T.S., Woods, R., Petraroli, M. and Sudarshan, T.S. 2002. An investigation of the influence of powder particle size on microstructure and hardness of bulk samples of tungsten carbide. Powder Technology, vol. 122. pp. 54-60.

Todd, I. and Sidambe, A T. 2013. Developments in metal injection moulding (MIM). Advances in Powder Metallurgy: Properties, Processing and Applications. Chang, I and Zhao, Y. (eds.). Woodhead, Sheffield. pp. 109-146.

YE, H., LIU, X.Y. and Hong, H. 2008. Sintering of 17-4PH stainless steel feedstock for metal injection molding. Materials Letters, vol. 62, no. 19. pp. 3334-3336. 